\title{
Training robotic surgery in urology: experience and opinions of robot urologists
}

Citation for published version (APA):

Brinkman, W. M., Schout, B. M. A., Rietbergen, J. B., de Vries, A. H., van der Poel, H. G., Koldewijn, E. L., Witjes, J. A., \& van Merrienboer, J. J. G. (2015). Training robotic surgery in urology: experience and opinions of robot urologists. International Journal of Medical Robotics and Computer Assisted Surgery, 11(3), 308-318. https://doi.org/10.1002/rcs.1631

Document status and date:

Published: 01/09/2015

DOI:

$10.1002 /$ rcs. 1631

Document Version:

Publisher's PDF, also known as Version of record

Document license:

Taverne

Please check the document version of this publication:

- A submitted manuscript is the version of the article upon submission and before peer-review. There can be important differences between the submitted version and the official published version of record.

People interested in the research are advised to contact the author for the final version of the publication, or visit the DOI to the publisher's website.

- The final author version and the galley proof are versions of the publication after peer review.

- The final published version features the final layout of the paper including the volume, issue and page numbers.

Link to publication

\footnotetext{
General rights rights.

- You may freely distribute the URL identifying the publication in the public portal. please follow below link for the End User Agreement:

www.umlib.nl/taverne-license

Take down policy

If you believe that this document breaches copyright please contact us at:

repository@maastrichtuniversity.nl

providing details and we will investigate your claim.
}

Copyright and moral rights for the publications made accessible in the public portal are retained by the authors and/or other copyright owners and it is a condition of accessing publications that users recognise and abide by the legal requirements associated with these

- Users may download and print one copy of any publication from the public portal for the purpose of private study or research.

- You may not further distribute the material or use it for any profit-making activity or commercial gain

If the publication is distributed under the terms of Article $25 \mathrm{fa}$ of the Dutch Copyright Act, indicated by the "Taverne" license above, 


\section{Training robotic surgery in urology: experience and opinions of robot urologists}

W. M. Brinkman ${ }^{1 *}$

B. M. A. Schout ${ }^{2,3}$

J. B. Rietbergen ${ }^{4}$

A. H. de Vries ${ }^{1}$

H. G. van der Poel ${ }^{4,5}$

E. L. Koldewijn ${ }^{1,6}$

J. A. Witjes ${ }^{7}$

J. J. G. van Merriënboer ${ }^{6}$

${ }^{1}$ Department of Urology, Catharina Hospital Eindhoven, The Netherlands

${ }^{2}$ Department of Urology, Medical Centre Alkmaar, The Netherlands

${ }^{3}$ EMGO Institute, VU Medical Centre Amsterdam, The Netherlands

${ }^{4}$ Department of Urology, Sint Franciscus Gasthuis, Rotterdam, The Netherlands

${ }^{5}$ Department of Urology, Netherlands Cancer Institute, Amsterdam, The Netherlands

${ }^{6}$ Department of Educational Development and Research, FHML, Maastricht University, The Netherlands

${ }^{7}$ Department of Urology, Radboud University Nijmegen Medical Centre, The Netherlands

*Correspondence to: W. M. Brinkman, Department of Urology, Catharina Hospital Eindhoven, Michelangelolaan 2, 5623 EJ Eindhoven, The Netherlands. E-mail: wmbrinkman@gmail.com

Accepted: 23 September 2014

\begin{abstract}
Background To answer the research questions: (a) what were the training pathways followed by the first generation of robot urologists; and (b) what are their opinions on the ideal training for the future generation?
\end{abstract}

Methods Data were gathered with a questionnaire and semi-structured interviews in a mixed-method research design.

Results The results show that training approaches differed from hardly any formal training to complete self-initiated training programmes, with all available learning resources. The median number of supervised procedures at the start of robot-assisted laparoscopy was five (range 0-100). Before patientrelated console time, respondents indicated that the minimum training of robot trainees should consist of: live observations ( $94 \%$ indicated this as essential), video observations (90\%), knowledge (88\%), table assisting (87\%) and basic skills (70\%).

Conclusion The first generation of robot urologists used different training approaches to start robotic surgery. There is a need for a structured and compulsory training programme for robotic surgery. Copyright (C) 2014 John Wiley \& Sons, Ltd.

Keywords robot training; expert opinion; interview

\section{Introduction}

The introduction of the da Vinci ${ }^{\circledR}$ surgical system by Intuitive Surgical in 2000 has changed the field of minimally invasive urology $(1,2)$. The use of this advanced technological device has accelerated the shift from conventional open surgery to minimally invasive surgery and has led to a completely different spectrum of required skills for the urological surgeon. Although the marketing of the da Vinci surgical system was focused on 'intuitive' usability, it has been shown that there are several technical difficulties and possible dangers of using this technically complex device, and that there is a learning curve (3).

The classic but still most common approach to training surgical skills is master-apprenticeship learning, which is characterized by trainees (postgraduate, novice, apprentice) learning surgical skills by practising directly on patients under the supervision of a 'master' or supervisor. However, this educational strategy is 
not compatible with the introduction of radically new technologies; being the pioneer of a new technique forces professionals to start operating on patients without the supervision of a master, simply because experienced colleagues are not yet available. At the same time, new technological devices that are clinically introduced and used are often only included in training programmes for fellows and residents after widespread acceptance.

Learning to perform robot-assisted laparoscopy can be divided into two broad facets (3), that of familiarization with the device before clinical use, and that of learning to perform specific operations. Theoretically, the situation is simple if a fully trained and competent laparoscopic urologist begins robot-assisted laparoscopy clinically. In this case, it seems simply a matter of adding knowledge about the robot to an existing set of minimally invasive skills. However, the situation is different for urologists or urologists-in-training who elect to begin using the robot without prior laparoscopic or open experience. In this situation, the two facets, familiarization with the device and learning the procedure, go hand in hand. While the first generation of urologists had to learn robot-assisted laparoscopy without a supervisor in their hospital, there is now a shift to a next generation that has the possible advantage of a supervisor in their hospital. This study aims to answer to following research questions: (a) what were the training pathways followed by the first generation of robot urologists; and (2) what are their opinions on the ideal training for the future generation?

\section{Materials and methods}

We used a mixed-method research design with quantitative data collected by means of an online questionnaire and qualitative data collected in semi-structured interviews.

\section{Participants}

Subscribers to the EAU robot urology section (ERUS) mailing list were invited to complete the online questionnaire if they were currently active as robot urologists or if they had previous experience in robot-assisted laparoscopy. The final question was whether the respondent would be willing to participate in an interview. Of those who agreed to participate, a cross-European group of robot urologists was selected.

\section{Questionnaire}

The questionnaire contained 19 multiple-choice and Likertscale questions (five-point scale: $1=$ not important at all to
$5=$ very important; Figure 3 ). It consisted of three parts. The first part focused on demographic data, e.g. year of start with robot-assisted laparoscopy and number of procedures performed. The second part contained questions about the training the robot urologists completed, e.g. what kind of training they received, how many hours they spent training and how many procedures they performed under supervision. The third part elicited their opinions on how an ideal robot training should be organized, e.g. what kind of training a future generation should receive, what the minimum of training should be for a future generation and how the respondents would rate the different training components.

\section{Interviews}

An interview protocol was developed, based on three main themes, experience in training, preferred way of pre-patientrelated learning and opinions on patient-related learning. The contents of the interview protocol were validated by further consensus in the research group, which consisted of clinicians and educationalists. Pilot interviews were conducted with two urologists and one urologist in training. During March-May 2013 the semi-structured interviews were conducted. Participants were a cross-European group of robot urologists who responded to the questionnaire and indicated they were willing to participate in an interview. The interviews were conducted by the principal researcher (W.B.). All interviews were one-on-one interviews that were audio-taped. Interviews were conducted by telephone or in person during the EAU meeting 2013 in Milan, Italy, or in the office workplace of the interviewee. Participation was voluntary and informed consent was obtained, with the assurance of anonymity throughout the study.

\section{Data analysis}

Pearson's correlation coefficient was used for the level of correlation between answers of the questionnaire. All audio-recorded interviews were transcribed verbatim by an independent secretary and rechecked with the recordings to ensure accuracy. Subsequently, transcripts were imported into a software program for qualitative data analysis (Atlas.ti v. 7). The transcripts were thematically coded by the principal researcher (W.B.), using a predefined coding scheme based on the questionnaire results and the three main themes: experienced training; preferred way of pre-patient-related learning; and opinion on patient related learning. To measure interobserver reliability, $25 \%$ of transcripts were independently coded by a second researcher (A.H.d.V.); reliability turned out to be sufficient (Cohen's $\kappa=0.74$ ). Thereafter, all 
interviews were summarized, using the final coding scheme. The responses were categorized into the three themes. Finally, quotes were selected to illustrate findings.

\section{Results}

The questionnaire was completed by 164 persons, 97 of whom belonged to the target audience (practising robot urologists, $n=89$; previous robot surgery experience, $n=8$ ). Median year of start with robot-assisted laparoscopy was 2010 (range 2000-2012), median age was 43 (range 31-64) years and $93 \%$ of respondents were male. Experience and training characteristics of the respondents are given in Table 1. Of the respondents to the questionnaire, 51 indicated they were willing to participate in the interview. We continued the interviews until saturation (no additional information) was reached. In total, 11 interviews were conducted. The interviews lasted a median of 20 (range 12-33) min.

\section{Training experience of the first generation of robot urologists}

All participants prepared themselves for robotic surgery by doing some form of training. Seven of 11 interviewed urologists had a background in laparoscopy; 4/11 switched from open surgery to robot-assisted laparoscopy. The questionnaire results and interviews revealed that training approaches differed from 1 or 2 days of training to a

Table 1. Experience and training characteristics of robot urologists $(n=97)$

\begin{tabular}{lcc}
\hline & $\begin{array}{c}\text { Participants } \\
(\%)\end{array}$ & $\begin{array}{c}\text { Median } \\
(\text { min-max })\end{array}$ \\
\hline $\begin{array}{l}\text { Procedure performed } \\
\text { RA laparoscopic } \\
\text { prostatecomy }\end{array}$ & 82 & $80.0(0-2700)$ \\
RA (partial) nephrectomy & 54 & $10.0(0-320)$ \\
RA pyeloplasty & 61 & $3.0(0-250)$ \\
RA cystectomy & 32 & $0.0(0-300)$ \\
RA ureteral re-implantation & 25 & $0.0(0-20)$ \\
RA colpopromontofixation/ & 14 & $0.0(0-150)$ \\
sacrocolpopexy & & \\
RA adrenalectomy & 14 & $0.0(0-12)$ \\
Types of training experienced & & Median days spent \\
& & $($ min-max) \\
Live observations & 90.0 & $5.0(0-50)$ \\
Video observations & 94.3 & $3.5(0-40)$ \\
Table assisting & 71.4 & $3.0(0-50)$ \\
Knowledge & 81.4 & $1.5(0-25)$ \\
Dry-lab basic skills & 78.6 & $1.0(0-15)$ \\
Dry-lab procedural steps & 60.3 & $0.5(0-15)$ \\
Animal & 61.4 & $0.5(0-10)$ \\
Virtual reality basic skills & 30.4 & $0.0(0-15)$ \\
Cadaveric training & 16.5 & $0.0(0-14)$ \\
\hline
\end{tabular}

complete, self-initiated, criterion-based training programme, with all available learning resources and for many hours.

According to the questionnaire results, $94.4 \%$ of the participants were supervised during a median of 5.0 procedures. The number of supervised procedures was not correlated to the year of start with robot-assisted laparoscopy (Pearsons's $\sigma=-0.17$ ). They indicated that the training they performed provided some basic knowledge and familiarization with the robot before performing the first procedure $(6 / 11)$,

Of all the interviewed urologists, $2 / 11$ declared that there was no lack in their preparation, and 4/11 indicated that they would have preferred a supervisor for more cases; 3/11 interviewees stated that there was a lack of structure in training when they were starting.

The number of procedures to be performed before feeling completely comfortable with the console greatly differed between the interviewees. One interviewee of 11 declared that he felt completely comfortable after four supervised procedures; three interviewees felt comfortable after 10 procedures; four interviewees felt comfortable after 20 procedures, and three interviewees felt comfortable only after 50 procedures.

\section{Opinions on future training}

According to the respondents to the questionnaire, the most important training components for future training were supervision (mean $=4.7$ on a five-point scale), live observations (4.4), video observations (4.3) and table assisting (4.4).

Minimum training components before allowing the trainee to sit at the console consisted of live observations ( $94 \%$ of the respondents indicated this as essential), video observations (90\%), knowledge training (88\%), table assisting (87\%) and dry-lab training of basic skills (70\%; see Figure 1).

Opinions of the interviewees were divided on setting an examination before patient-related learning. Most participants indicated that trainees should complete their knowledge training and basic skills training to proficiency level $(7 / 11)$ before performing procedures on patients. To quote one of them:

'In a Playstation game, you can't go to the next level until you have completed the task. You could set parameters: you are not allowed to do the anastomosis until you can do it in the simulator in 20 minutes. That would make people do their homework'.

Five of 11 participants indicated that, besides objective parameters, the judgement of the supervisor remains important in an examination. 


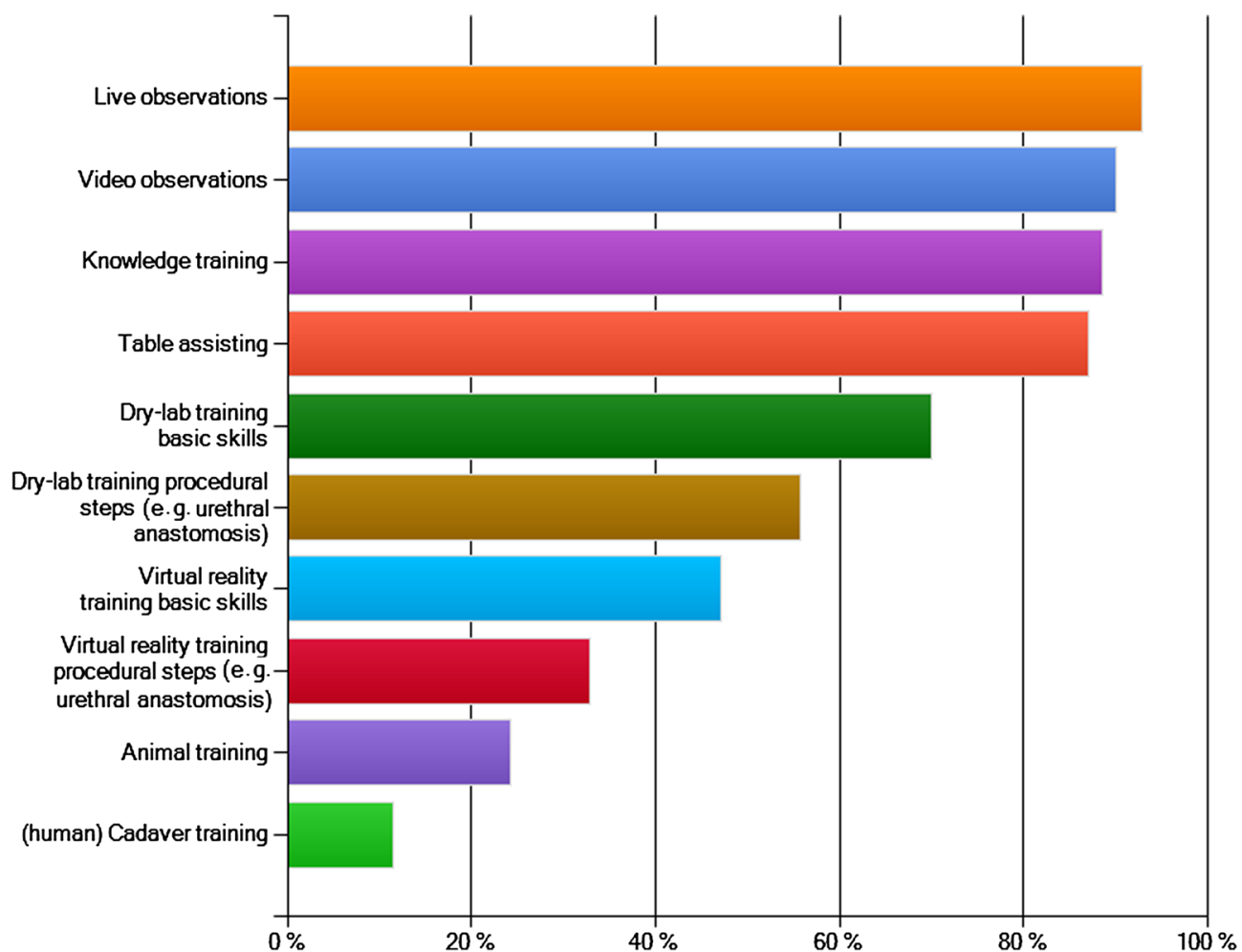

Figure 1. Minimum of training for residents or fellows, before patient-related console time indicated in questionnaire

One question was 'what could be a reason to stop someone from being trained to become a robot surgeon?' Three of 11 interviewed robot urologists indicated that if you set a test on basic skills and knowledge and trainees fail the test, they should be stopped. One participant said: 'If you don't pass the test, you need to say, please come

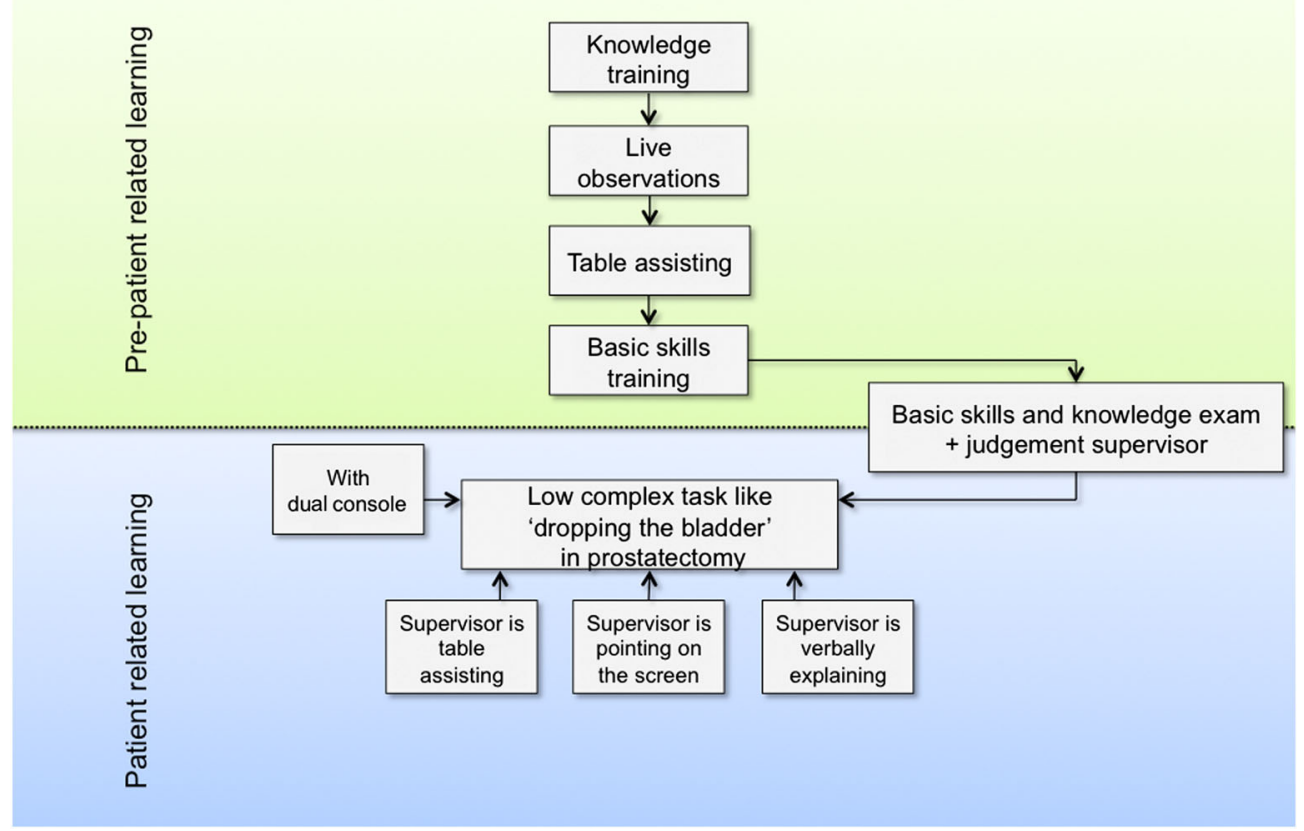

Figure 2. Flow-chart of opinion of robot urologists on how to start robotics 


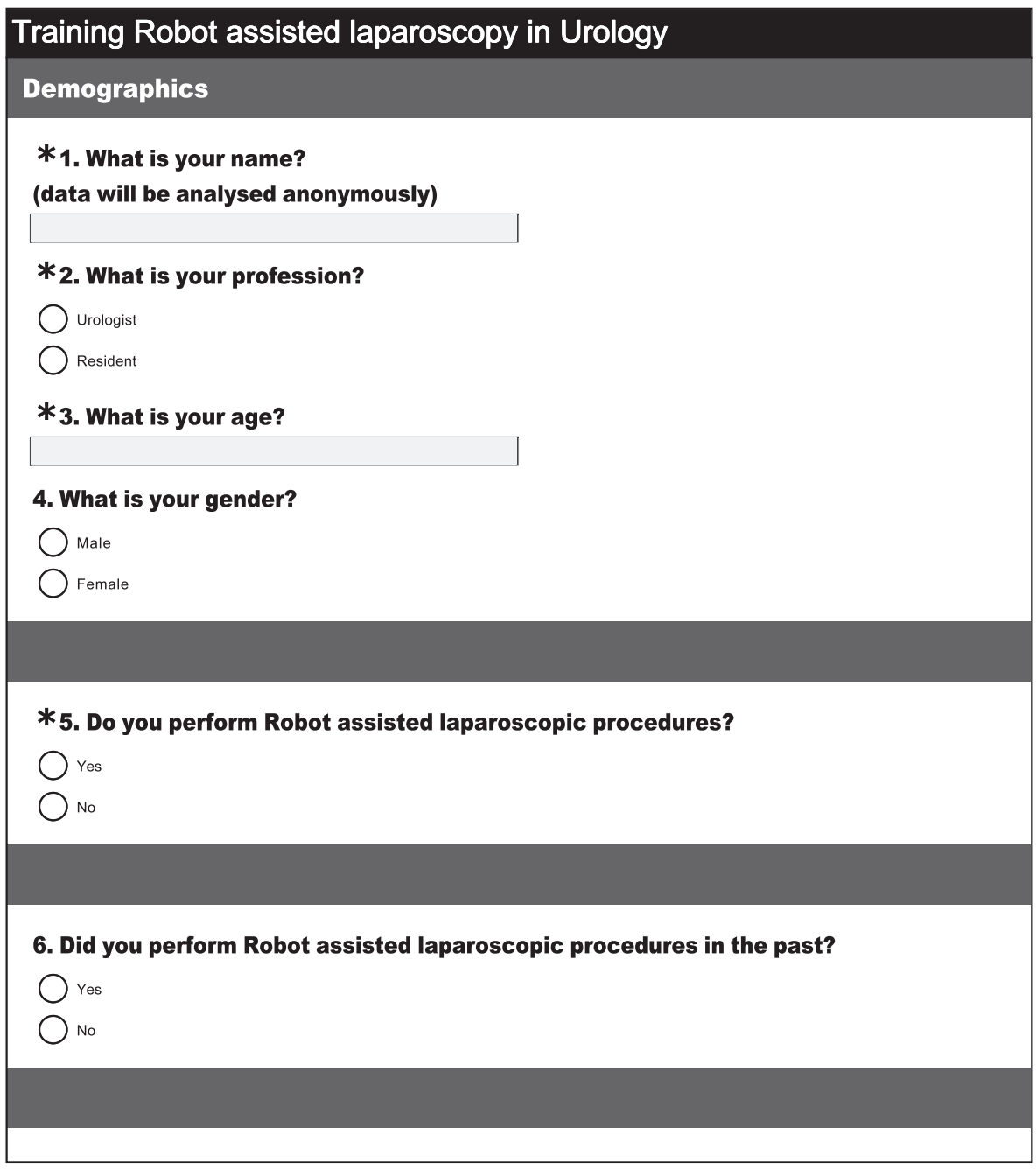

Figure 3. Questionnaire completed by the robot urologists

back 6 months later'. Others indicated failure to progress $(3 / 11)$ or loss of control (3/11) in patient-related learning. One of the interviewees could not think of a reason to stop anyone and felt that everybody could learn robotic surgery.

\section{Patient-related learning}

The majority of the interviewees indicated 'dropping the bladder' in the robot-assisted radical prostatectomy as an ideal first step in patient-related learning (9/11). According to the respondents, the task of the supervisor would be to verbally explain $(8 / 11)$ and to point out directions on the screen (4/11), ideally with the help of a dual console $(3 / 11)$ or as a table assistant (4/11) (Figure 2)

Some robot urologists indicated that if they started a new procedure, a procedure they did not perform with robot assistance, e.g. a cystectomy, they would just start without any extra preparation (2/11) Most of the participants stated that they would watch videos $(7 / 11)$, go and observe others (8/11) and request supervision (7/11).

\section{Discussion}

The results of this study reveal large differences in preparation for the first robotic procedures performed by the first generation of robot urologist. Preparations range from: 'I just started, it's like driving a new car' to complete a selfinitiated, criterion-based training programme with all available learning resources, such as video observations, live observations, cadaveric training, dry-lab training, procedural training and team training. Although some surgeons state that changing from laparoscopy to robot-assisted laparoscopy only made the procedure easier, slow learning curves, based on operating time, complication rates and 


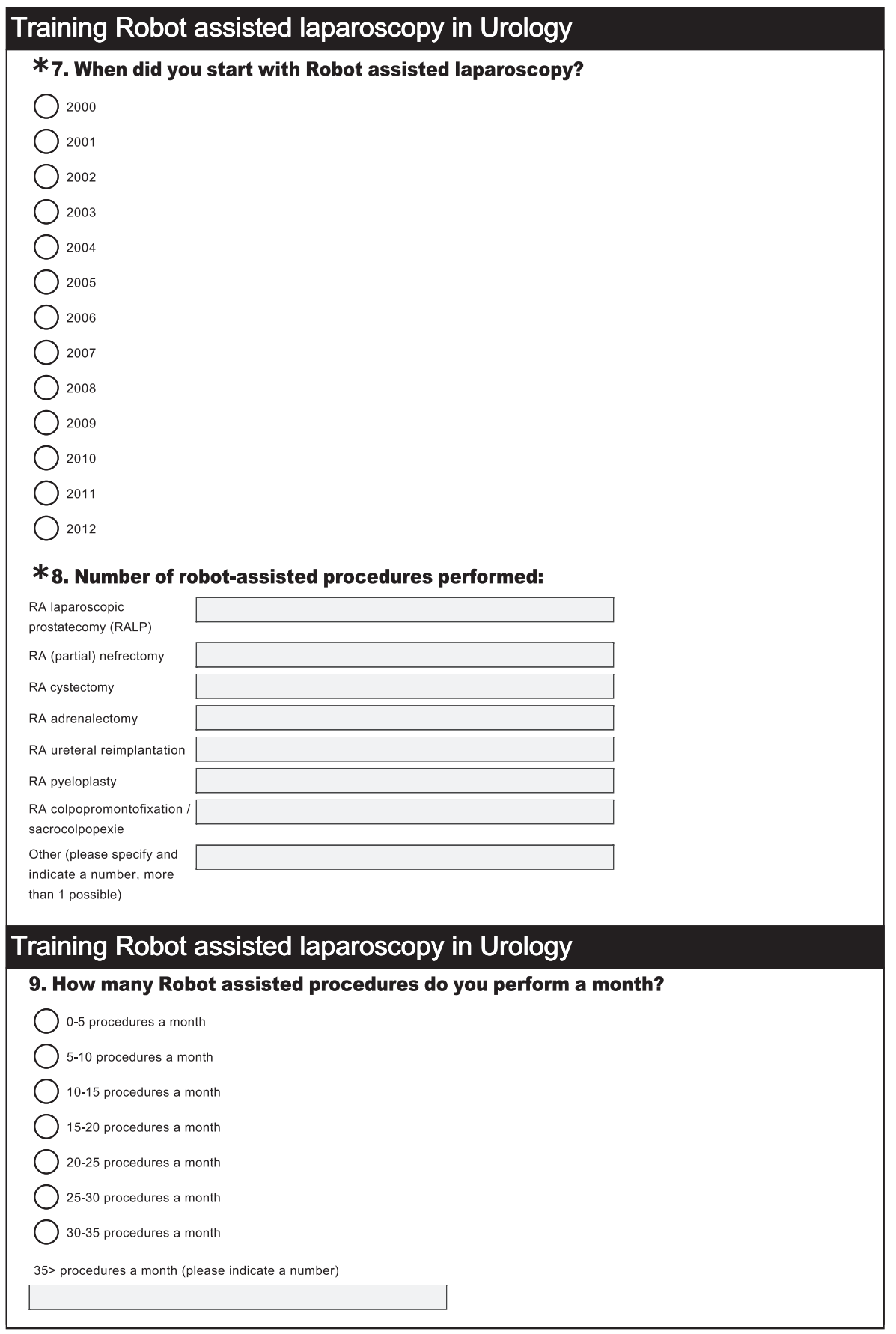

Figure 3. (Continued)

surgical margins of up to 200 procedures have been described, even for those operators transferring from laparoscopy $(4,5)$. Serious complications, such as lower limb compartment syndrome, are described for robot-assisted laparoscopy and seem to be related to suboptimal learning, i.e. inexperienced operators and prolonged operating time (6).

Although ideal training programmes have been described in the literature $(7,8)$, this study describes the actual training performed by the pioneers in robot urology. It shows that most robot urologists emphasize the need for a structured training programme. Knowledge training, observations, table assisting and basic skills training are highly recommended for the next generation (Figure 2). Surprisingly, dry-lab training is more popular than virtual reality training. Possibly this is due to the fact that the virtual reality simulator is not yet widely used 


\section{Robot training experience first generation}

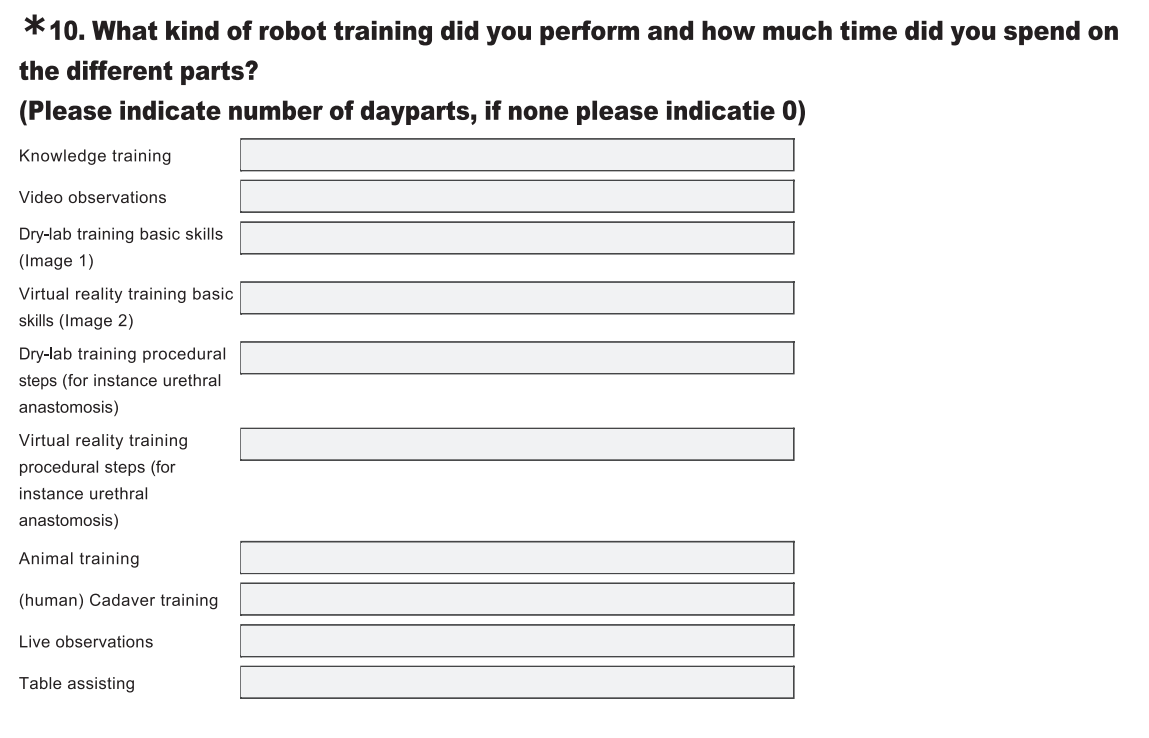

Training Robot assisted laparoscopy in Urology

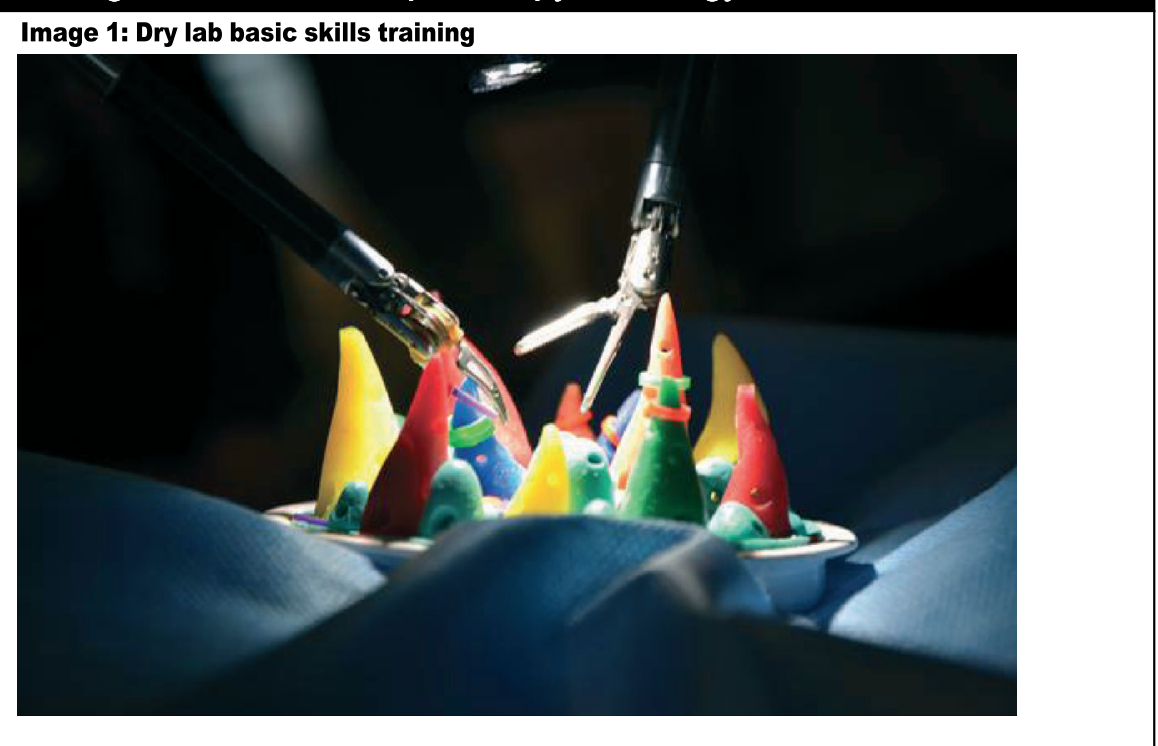

Figure 3. (Continued)

and thus not all robot urologists are familiar with this device. Recent literature (9) reviewed the effectiveness of simulation in the initial phase of training robotics, and virtual reality simulation for robotic surgery seems as least as effective as dry-lab training (10). (Figure 3)

The literature suggests that controlled patient-related learning by supervision does not have to negatively impact patient outcomes of robotic surgery $(11,12)$. Furthermore, a structured training programme leads to an increase in robotic cases, and participants positively rated training prior to initiating robotic surgery (13).
The first robot urologists highly recommended supervision for the next generation. Their positive opinion about supervision seems to be in contrast with the reported median of only five supervised cases. Retrospectively, the urologists indicated that they would have liked to have more supervision. Five supervised procedures seem insufficient to overcome the initial and steepest part of the learning curve and, according to most interviewees, they are even insufficient to feel completely comfortable with the console.

Another remarkable finding is that, although a great portion of robot urologists performed animal training, 


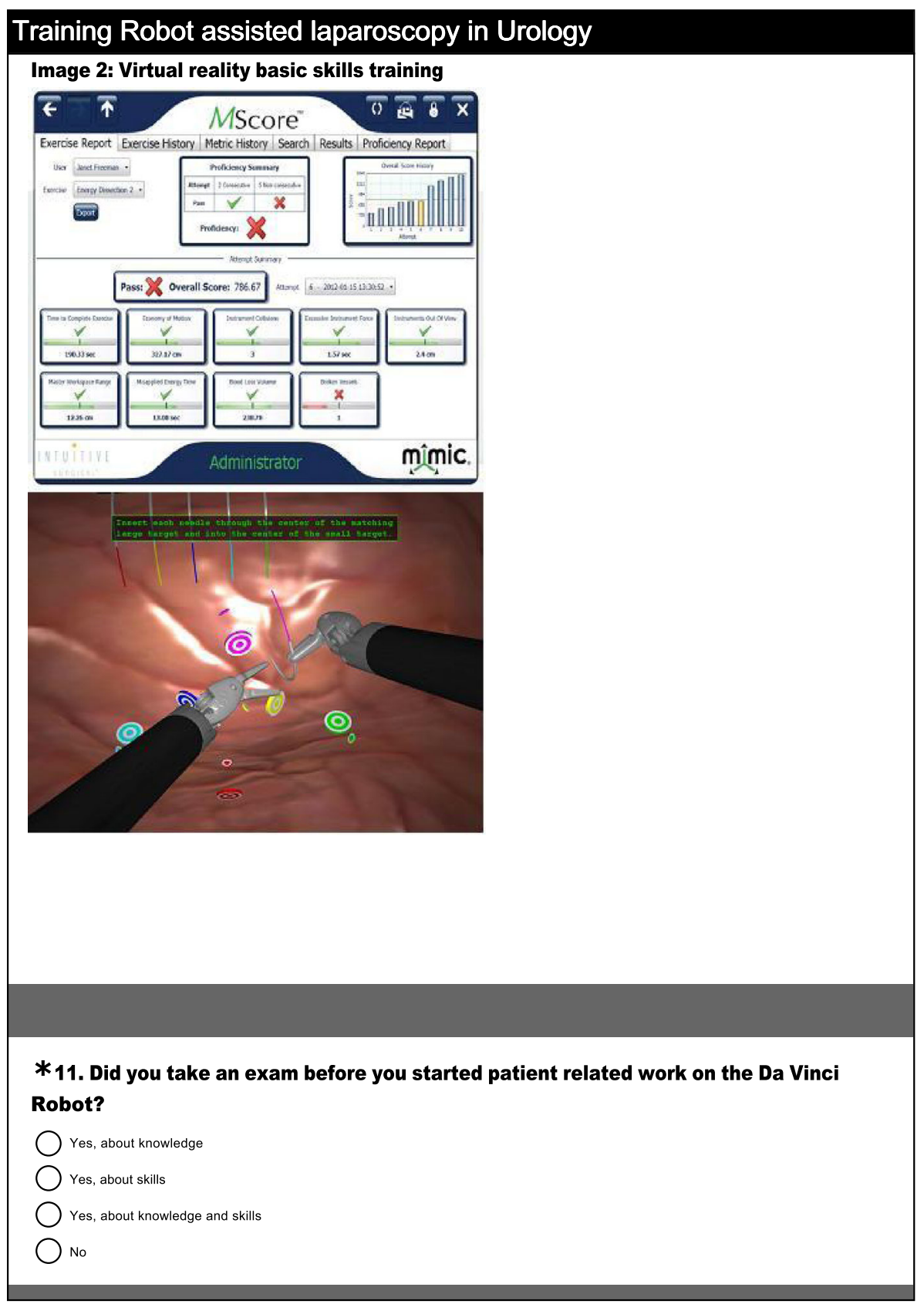

Figure 3. (Continued)

they do not indicate this as very important or necessary for a new generation. A possible explanation for this could be that the evidence for the effectiveness of animal training is scarce; it has limitations of speciesspecific anatomy and usually no pathology. Skills that can be learned on an animal model can possibly also be learned in a dry-lab or virtual-reality setting. Another reason could be practical: the costs of animal training are high, and most institutions do not have an animal laboratory. In some countries, animal training is even legally forbidden (14).
The results of this study show that recommendations of the first generation of robot urologists for future training differ from their own experiences. This indicates that they judged their own training as suboptimal. Although some brought up the argument that no supervisor was available, since they were the very first robot urologists, most others decided not to do a fellowship or to undergo a supervision period of more than five procedures. Besides, although virtual reality simulators did not exist in the very beginning, dry-lab training was widely available, but not extensively used, by most of the participants. This study 


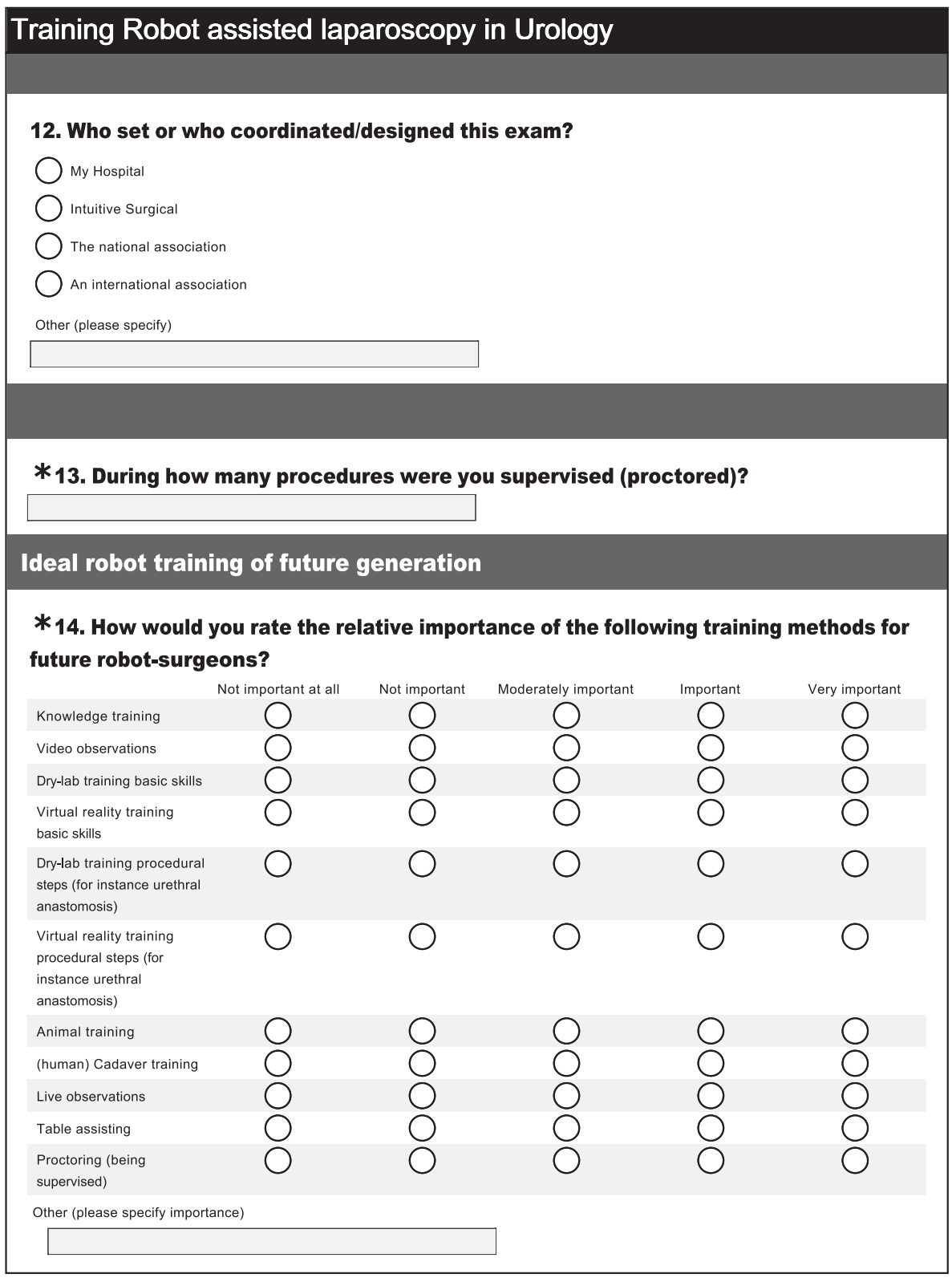

Figure 3. (Continued)

confirms the need for a structured and compulsory training programme that reduces the large differences in training efforts among practising robot urologists and guarantees the quality of care. Although the manufacturer of the da Vinci robot initiated training, this study reveals that a more thorough training programme supplementary to the training as given by Intuitive Surgical is desirable: the training provided by the manufacturer seems, according to the urologists, not sufficient to fully master the robot console.

Our study had some limitations. First, the group studied was selected from a large mailing list of individuals interested in robot urology. The participants were European robot urologists who were willing to complete a questionnaire or participate in an interview about their training. Possibly this led to a selection bias that influenced the reported opinions on training robotics. Second, the study group consisted of experts in robot urology, rather than of experts in robot training or education. Although they have experienced training themselves, it may have been difficult for them to know exactly what training components were the most beneficial for them. They probably do not have knowledge of what exists for training in other highly technical fields, such as aeronautics. Besides, this group may not have been aware of all the available evidence on training robotics. Therefore, when designing the ideal robot curriculum, educationalists should be involved and all separate components should be validated. 


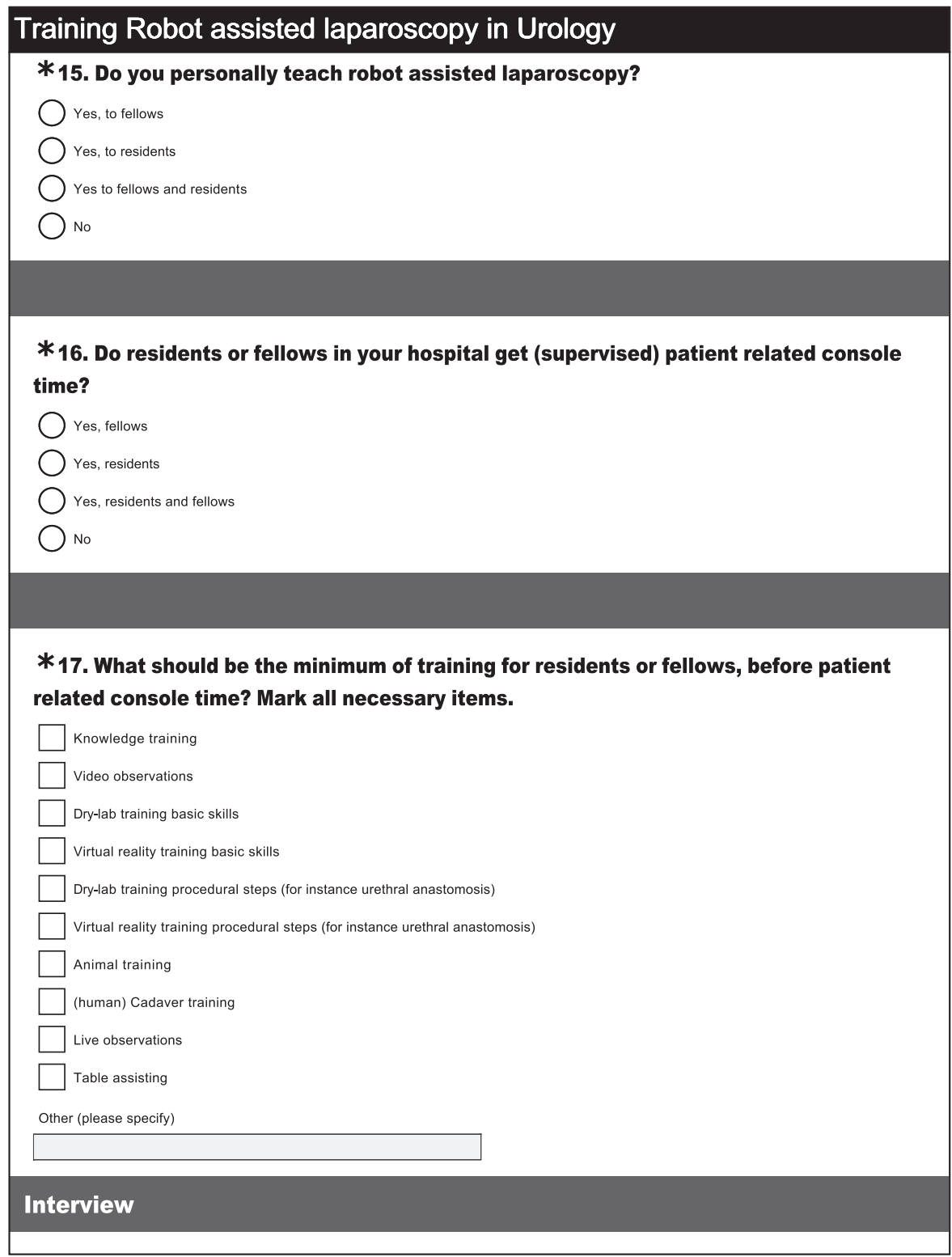

\begin{tabular}{l} 
Training Robot assisted laparoscopy in Urology \\
18. Your opinion is of great value to us. Therefore we would like to invite you for a one \\
on one interview to clarify your thoughts on robot training. Can we contact you to \\
schedule this interview? \\
Yes \\
No \\
\hline *19. What is your email address? \\
\hline \\
\hline
\end{tabular}

Figure 3. (Continued) 


\section{Conclusions}

European robot urologists of the first generation report to have taken different training approaches to starting robotic surgery. The main problems they experienced were the lack of a structured training programme and the limited availability of a supervisor. They endorse the need for a structured and compulsory training programme for robotic surgery, with clear criteria for knowledge training, basic skills training and modular, supervised, patient-related learning, to minimize the risk that patients pay the price for the surgeons' learning process.

\section{Acknowledgement}

The authors would like to thank Lisette van Hulst for her editorial assistance.

\section{Conflict of interest}

The authors have stated explicitly that there are no conflicts of interest in connection with this article.

\section{Funding}

No specific funding.

\section{References}

1. Zorn KC, Gofrit ON, Steinberg GD, et al. Evolution of robotic surgery in the treatment of localized prostate cancer. Curr Treat Options Oncol 2007; 8: 197-210.

2. Ahmed K, Khan MS, Vats A, et al. Current status of robotic assisted pelvic surgery and future developments. Int $J$ Surg 2009; 7: 431-440.

3. Herron D, Marohn M. A consensus document on robotic surgery. Surg Endosc 2008; 22: 313-325.

4. Ou YC, Yang CR, Wang J, et al. The learning curve for reducing complications of robotic-assisted laparoscopic radical prostatectomy by a single surgeon. BJU Int 2011; 108: 420-425.

5. Atug F, Castle EP, Srivastav SK, et al. Positive surgical margins in robotic-assisted radical prostatectomy: impact of learning curve on oncologic outcomes. Eur Urol 2006; 49: 866-872.

6. Pridgeon S, Bishop CV, Adshead J. Lower limb compartment syndrome as a complication of robot assisted radical prostatectomy: the UK experience. BJU Int 2013; 112: 485-488.

7. Schreuder HW, Wolswijk R, Zweemer RP, et al. Training and learning robotic surgery, time for a more structured approach: a systematic review. Br J Obstet Gynaecol 2012; 119: 137-149.

8. Lee JY, Mucksavage P, Sundaram CP, et al. Best practices for robotic surgery training and credentialing. $J$ Urol 2011; 185(4): 1191-1197.

9. Abboudi H, Khan MS, Aboumarzouk O, et al. Current status of validation for robotic surgery simulators; a systematic review. BJU Int 2013; 111: 194-205.

10. Hung AJ, Jayaratna IS, Teruya $\mathrm{K}$, et al. Comparative assessment of three standardized robotic surgery training methods. BJU Int 2013; 112: 864-871.

11. Davis JW, Kamat A, Munsell M, et al. Initial experience of teaching robot assisted radical prostatectomy to surgeons in training: can training be evaluated and standardized? BJU Int 2010; 105: 1148-1154.

12. Schroeck FR, Palha de Sousa CA, Kalman RA, et al. Trainees do not negatively impact the institutional learning curve for robotic prostatectomy, as characterized by operative time, estimated blood loss, and positive surgical margin rate. Urology 2008; 71: 597-601.

13. Altunrende F, Autorino R, Haber GP, et al. Immediate impact of a robotic kidney surgery course on attendees' practice patterns. Int J Med Rob Comput Assisted Surg 2011; 7: 165-169.

14. Cox M, Irby DM, Reznick RK, et al. Teaching surgical skills, changes in the wind. $N$ Eng $J$ Med 2006; 355: 2664-2669. 